\section{Research centres, libraries, flourish in new China}

Most Chinese scientists - indeed, the people as a whole - are friendly, forthcoming and purposeful, yet modest and earnest (sometimes to the point that reserved westerners find uncomfortable to reciprocate). Their optimism is derived from the positive and negative lessons of the Cultural Revolution (reputedly assessed by Chairman Mao to be $70 \%$ and $30 \%$ respectively), open discussions on present problems, and from a common resolve to achieve the four modernisations in agriculture, industry, national defence, and science and technology. To this aim, the political decision-making system is being scrutinised and modified to prevent the recurrence of a dictatorship by a minority, like that of the Gang of Four (GoF).

Both science and scientists suffered under the GoF. This was probably due not so much to deliberate policies as to the GoF's broadside attacks on "revisionism" and on people it labelled as "capitalistroaders". Although the GoF had some supporters its treachery became increasingly clear with time: its attacks

Researchers at the Institute of Applied Chemistry, Kirin, discussing the structure and performance of a new polymer

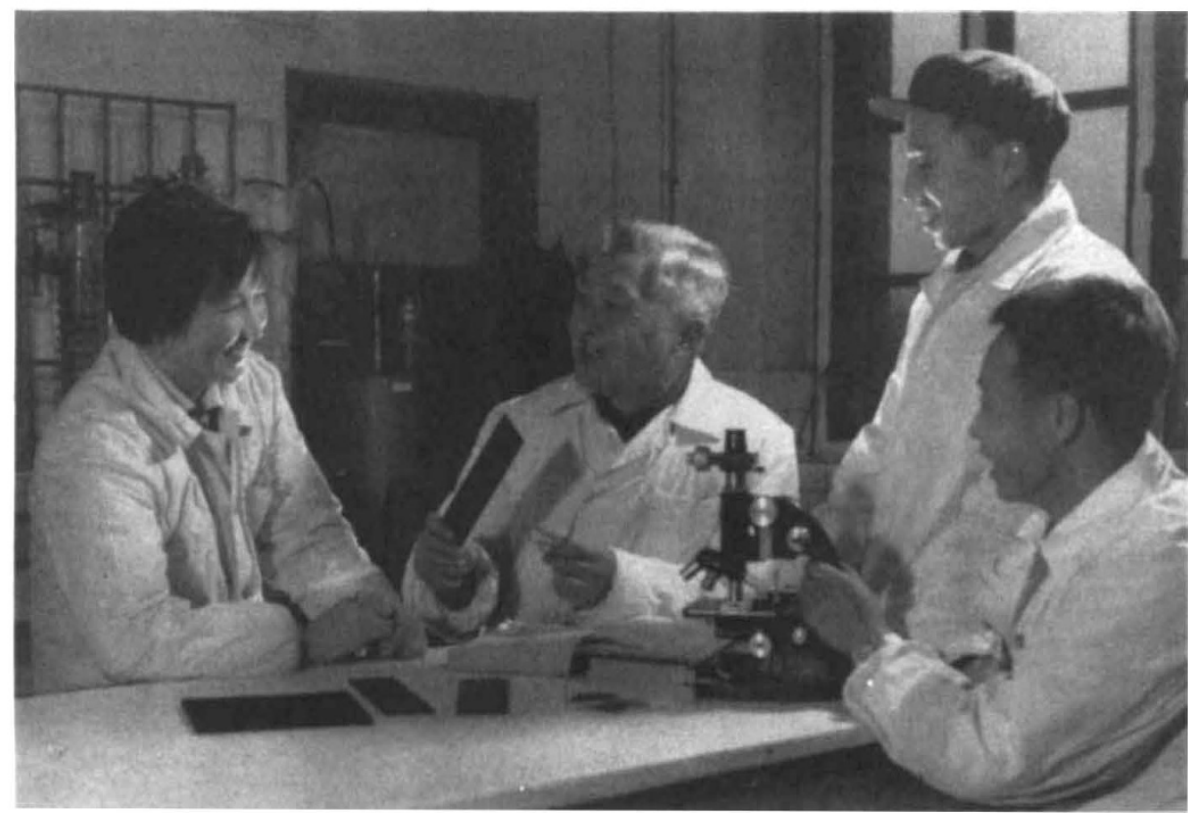

constituted the means rather than the end of its attempt to seize power. Sectarianism resulted and this reached a peak in 1975 when Mao condemned the factions semipublicly. The aim of the present leadership is an extended period of stability and economic construction. The conditions are right for the growth of science.

Not surprisingly the Scientific and Technical Association, which barely existed three years ago, is expanding. Often affectionately referred to as the 'home' of scientists, it sponsored some 150 meetings in 1978; the number last year exceeded 650 . The newest members include a futurology society and a solar energy society. As well as its function as a learned society, the association is responsible for the popularisation of science, which I shall talk about next week. Neither it nor any of its member societies acts as a qualifying body.

After the reopening of their 'home', our Chinese colleagues are also benefiting from other improvements. Problems had included insufficient time for research owing to a shortage of assistants and too many administrative commitments and functional. In general there are still not enough instruments yet, reassuringly, for the most part they are designed and produced in China. Laboratories may look run-down, but everyone using them knows exactly how the equipment works. Usually every bit of the equipment has not only been designed and built by the experimenters but is also maintained by them. Of course, there are some negative aspects. In a few places I noticed, for example, that resources appeared underused. But the main feeling is one of optimism.

Most Chinese scientists (some 25,000 out of 36,000 of those in the Academia's institutes) were trained after the Liberation and before the Cultural Revolution. They were educated by teachers produced by the old social system; through remoulding and re-education, however, they are judged to have become "part of the proletariat" now that the gap between manual and professional labour is considered overcome. Many scientists are commended 
as advanced workers and are thus entitled to wage increments (the latest nationwide wage increase, on 1 November, was for $40 \%$ of state employees.) More important, more scientists are now allowed Party membership; they can be elected as deputies to the National People's Congress, or appointed to authoritative positions. In the past decade, a career structure, by qualification and seniority, has been designed and scientists can look foward to promotion.

A few institutions now adopt the convention that the authorship of papers will serve as a simple criterion of a member's contribution. All journals in China are, of course, published by the state and they have mandatory rankings, a paper in Scientia Sinica carrying the most weight. This may encourage the formation of selfcentred sub-groups each pursuing prestigious research; the decline of collective authorship in the journals could be a reflection of this. More inventively, some institutions pursue the practice of arranging exhibitions of research results. All members are invited to assign "work points' to the research on display according to personal judgements of its quality. Promotions are decided by the institution's 'academic committee' which refers to these collective evaluations. Some institutes also organise symposia at which their research is described and then discussed by coworkers invited from other institutes or universities.

Since 1978 , scientists have been paid by the state for papers published whereas in the previous decade not even authors of books received royalties. Much stress is being laid on information science. Last August the China Society of Libraries was formed. Some of the larger university libraries plan to be computerised within a few years. Also in 1978 the Scientific and Technological Literature Press began issuing, for a whole range of subjects, monthly and bimonthly indices of foreign papers and specifications of open patents being applied for in Japan.

A national shortage of wood and wood pulp has constrained the publication of books and periodicals but is slowly being overcome. China now publishes a total of 1,200 periodicals in all areas and more will probably be launched. In electronics and communications technology, for example, there are some 20 primary journals with a general circulation. I also saw the following titles which are exclusively devoted to classical disciplines within physics: Acta Physica Sinica, Wuli (physics), Acta Mechanica Sinica, Mechanics \& Practice, Acta Acustica, Luminescence in Solids \& its Application, Laser Journal, Gaofengzi Wuli (high polymer physics), Diwen Wuli (low temperature physics), and Physica Energiae Fortis \& Physica Nuclearis.

Foreign journals are also used. Because of their high costs, however, most of them are centrally subscribed by airmail and then reprinted, the home-produced versions

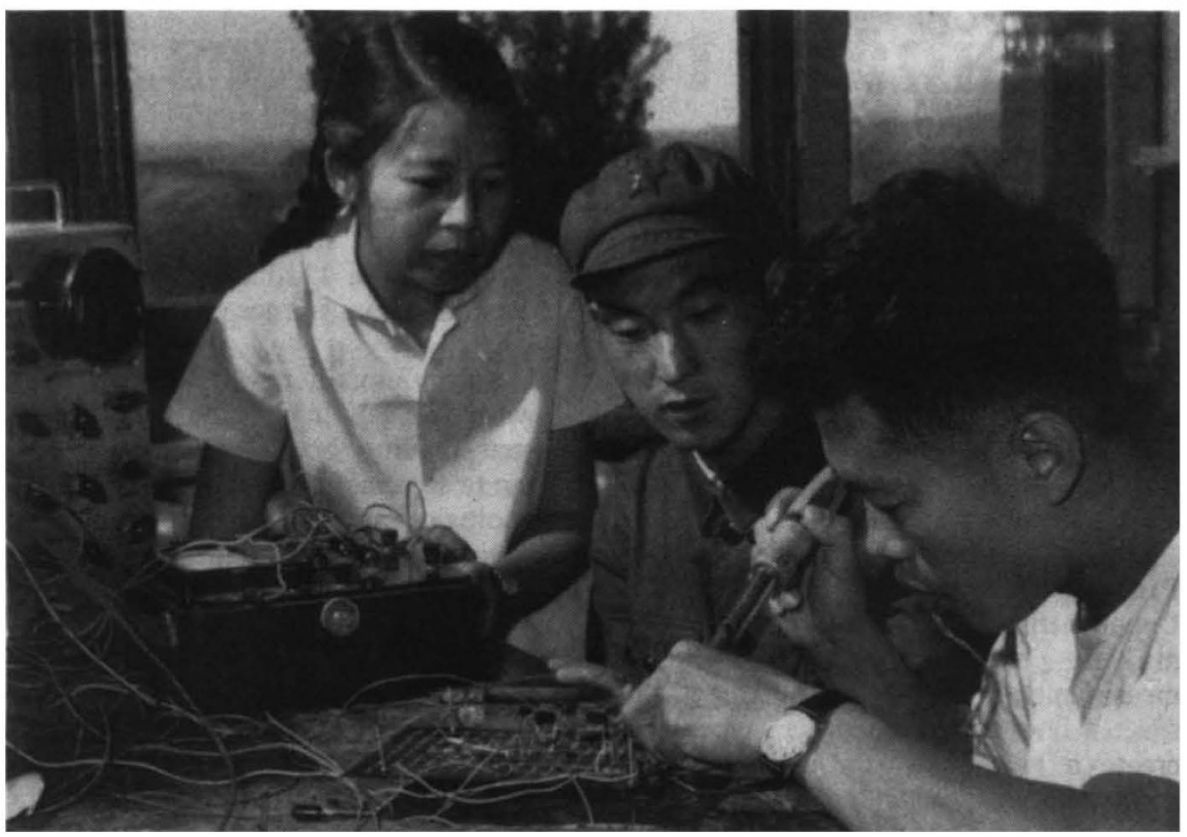

Students at the University of Science and Engineering, Tsinghua, engaged in an electronics experiment

then being nationally distributed. The copies usually manage to reach the library shelves with no more than a few months' delay. There are no cover-to-cover translations into Chinese, and some readers may find this a problem.

The language problem can also affect visiting scholars. Speakers may find that their talks and the subsequent questions and answers are translated verbatim, sentence by sentence, with the help of the entire audience. Despite such difficulties, it is certainly a positive development that visits, in either direction, are increasing in both frequency and in the variety of disciplines covered.

'Centres of Scientific and Technical Exchange with Foreign Countries' have been set up in Beijing, Shenyang, Shanghai and Guangzhou (Canton) to assist the Foreign Affairs Bureau of the Academia Sinica and the Ministry of Education with scientific exchanges. The Scientific and Technical Association also oversees exchanges. Together with the US Committee on Scholarly Communication with the People's Republic of China (PRC), it is arranging for senior scientists as well as graduate students to stay for extended periods in China and participate in joint programmes. Sino-British cooperation in education, public health and culture was sealed by a five-year agreement signed at 10 Downing Street on 1 November 1979 during Hua's visit.

China now hosts international conferences more often, examples being the International Rice Research Workshop at the end of October last year in Guangzhou, and one on particle physics one month ago, at the same venue, under the chairmanship of Qian Sanqiang.

More than 1,600 academics, 180 research students and 420 undergraduates have been sent by China in the past two years to the US (500), UK (300), West Germany (200), France (200) and Japan (100). The overwhelming majority $(1,800)$ are studying natural sciences. Advanced crash courses in languages, more often needed than not, are given just before departure or immediately after arrival at the host country.

Language will not, of course, be a problem for visitors of ethnic Chinese origin if they can speak the standardised dialect. Some of them have established close contact, and are on the 'academic committees' of some institutions. Scientists such as Chen-Ning Yang, Nobel prizewinner for the discovery of the violation of parity conservation, have made particularly valuable contributions, by participating in or advising on research, and inspiring young people, as well as cultivating friendship between China and their adopted countries.

'Sister universities' constitute another novel form of overseas ties. Zinghua at Beijing is affiliated to the University of California at Berkeley, Zhongshan in Guangzhou to the University of California at Los Angeles, and Nanjing to the University of Wisconsin. China is taking part in more bilateral and international scientific programmes. Recent examples are the measurement of $\nu_{-} \mathrm{e}$ interaction cross-sections at the Fermi Laboratory and the Global Atmospheric Research Programme sponsored by the World Meteorological Organisation. As a result of these overseas links, increasing attendance at international meetings, and of submission's to western journals by Chinese scientists, it is now easy to find out who's doing what in the country. One source of information is the Directory of Scientific Research Institutes in PRC, produced by the National Council for US-China Trade in Washington, D.C. $\square$ 